\title{
SEX DIFFERENCES IN DIAMETER OF THE CORONARY SINUS OSTIUM: CORRELATION WITH WEIGHT OF THE HEART
}

Ominde Beryl S, Ogeng'o Julius A.

Correspondence to Dr. Beryl Ominde Department of Human Anatomy University of Nairobi, PO Box 30197 00100 Nairobi.

ABSTRACT
Diameter of the coronary sinus ostium is important in the designing of cannulation devices used in cardiac resynchronization therapy and percutaneous mitral valve annuloplasty. Population variation of the diameter may account for the failure rate of these procedures. Studies of the coronary sinus ostium from African populations are scarce and altogether absent for Kenya. Therefore, this study aimed at determining sex differences in the diameter of coronary sinus ostium and its correlation with the weight of the heart. Seventy-four hearts of adult black Kenyans [43 male, 31 females; age range 20 - 70 years] obtained during autopsy at the Department of Human Anatomy, University of Nairobi, Kenya were weighed. The coronary sinus ostium was identified and its transverse and supero-inferior diameters measured in millimeters. The measurements were analyzed using SPSS version 17. Sex comparison was established using student's t test. Association between diameter and heart weight was established using Pearson's correlation test and considered significant at a $p$-value of $\leq 0.05$. Data were presented using scatter plots. Transverse and supero-inferior diameters of the ostium were $11.04 \pm 1.88 \mathrm{~mm}$ and $9.50 \pm 1.80 \mathrm{~mm}$ respectively. The mean diameter was $10.27 \mathrm{~mm}$. These correlated positively with weight of the heart. When corrected for weight of the hearts, the transverse and supero-inferior diameters were larger in females ( 0.042 and 0.036 respectively) than in males ( 0.034 and 0.03 respectively). The diameter of coronary sinus ostium is larger in females and shows positive correlation with weight of the heart. These data should be considered during design and use of cardiac devices introduced through the coronary sinus.

Key words: Coronary sinus, ostium, diameter, sex difference.

\section{INTRODUCTION}

The ostium of coronary sinus (CS) opens into the right atrium between eustachian valve and tricuspid annulus (Felle et al., 1994; Cascade et al., 2001). Knowledge of CS dimensions is important for invasive and interventional cardiac treatment and management tools for common cardiac disorders (Habib et al., 2009; Koragoz et al., 2013). Of these dimensions, CS ostium is a key structure in the heart from the electrophysiologist's point of view (Mlynarski et al., 2011). Further, measurements of diameter of ostium of CS may be useful in identifying the mechanism of tachycardia before invasive electrophysiology study (Ezhumalai et al., 2014).
Gender differences in heart disorders (Glower et al., 2009) and CS blood flow rates (Zheng et al., 2013) suggest gender differences in dimensions of the ostium of CS. Morphometric data of CS from African populations is scanty and altogether absent for Kenya, though heart diseases that may require therapeutic and diagnostic intervention through the sinus are common (Yuko-Jowi, 2012; Watkins et al., 2012). Further, how the ostium diameters vary with gender and heart weight is not clearly established. Accordingly, this study aimed at describing sex differences in the CS ostial diameter and its correlation with heart weight.

Submitted $7^{\text {th }}$ June 2016, revised on $7^{\text {th }}$ September 2016. Published online $12^{\text {th }}$ January 2017. To cite: Ominde BS, Ogeng'o J A. Sex differences in diameter of the coronary sinus ostium: correlation with weight of the heart...862 -866. 


\section{MATERIALS AND METHODS}

This study was carried out at the Department of Human Anatomy, University of Nairobi. Ethical approval for the study was granted by the Kenyatta National Hospital-University of NairobiEthics and Research Committee. Seventy four hearts of adults Kenyans (43 males; 31 females; age range 20 - 70 years) obtained during autopsy were studied. The chest cavity was opened through costal cartilages incisions, the sternum removed and pericardium incised longitudinally to expose the heart. Harvesting of the heart was done by dividing the great vessels $2 \mathrm{~cm}$ from the superior extent of the heart's base. Heart specimens with any observable congenital defects, valvular vegetations, and cardiomegaly (above $450 \mathrm{~g}$ ) had been excluded from the study. The hearts were categorized according to sex and weighed in grams using an electronic weighing balance SF- $00^{\odot}$.

The ostium was identified as an oval opening of CS in the right atrial wall. The transverse and supero-inferior (SI) diameters of the ostium were measured using a pair of dividers and transferred to a ruler [see figure 1]. Data were recorded, tabulated and analyzed using

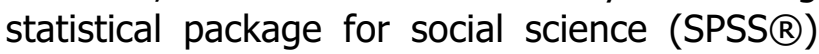
software Version 17.0, Chicago, Illinois and Microsoft Office Excel, 2007-Microsoft Corporation. Measurements were expressed in means and standard deviations. Association between various morphometric parameters was established using Pearson's correlation test. The diameters were standardized by dividing them with weight of heart. Using student's unpaired ttest, the standardized values obtained were used to compare sex differences. Student's t-test was used for comparison between SI and transverse diameters. A p-value of $\leq 0.05$ was considered significant at $95 \%$ confidence interval. Tables and scatter plots were used for data presentation.

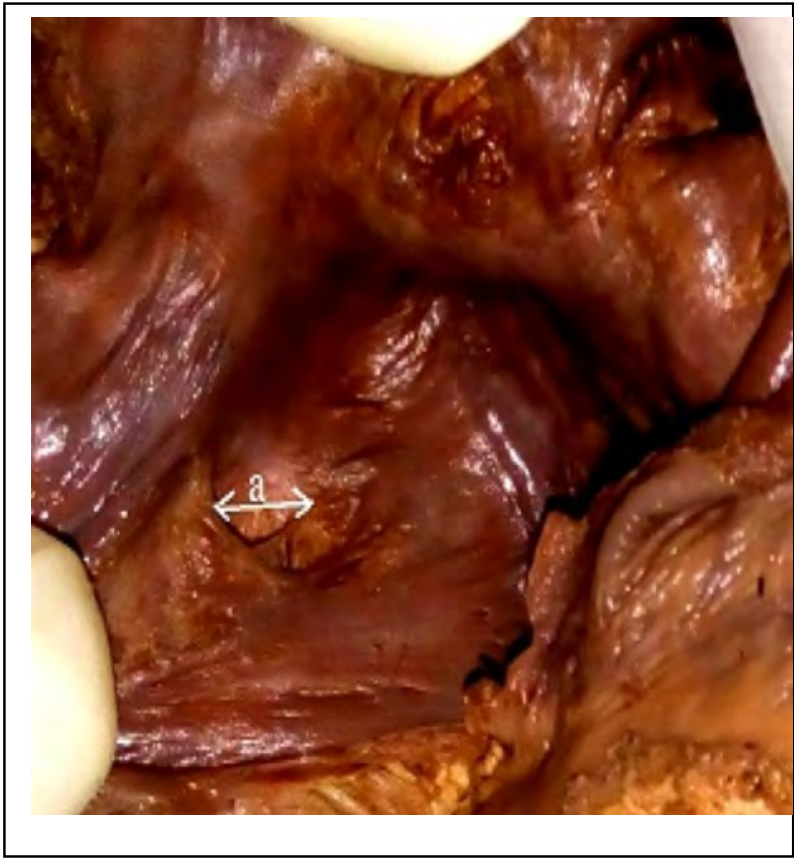

wall. a- transverse diameter, b-supero-inferior diameter.

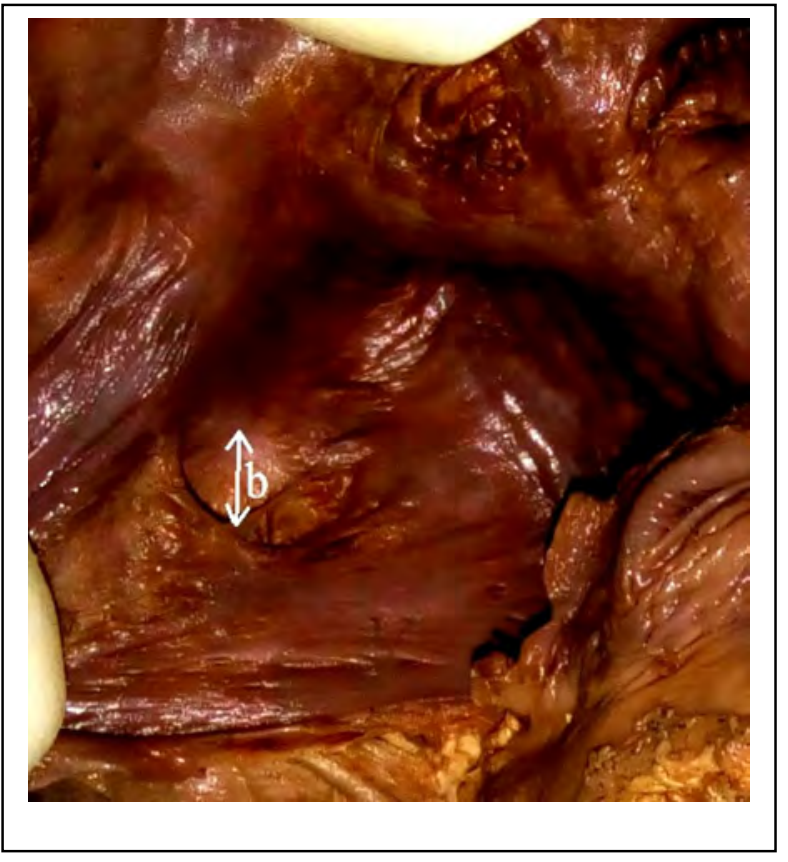

Figure 1 . Coronary sinus ostium in the right atrium 
Anatomy Journal of Africa. 2017. Vol 6 (1): $862-866$

\section{RESULTS}

In all cases, the CS originated at the point of confluence of great cardiac vein (GCV) and oblique vein of Marshall to terminate at the postero-inferior aspect of right atrium. The mean transverse diameter of the ostium was $11.04 \pm 1.88 \mathrm{~mm}$ (range $8-15 \mathrm{~mm}$ ); $11.07 \pm 1.86$ $\mathrm{mm}$ (range $8-15 \mathrm{~mm}$ ) in males and $11.00 \pm 1.94$ $\mathrm{mm}$ (range $8-15 \mathrm{~mm}$ ) in females $(\mathrm{p}=0.876)$. The mean supero-inferior (SI) diameter on the other hand was $9.50 \pm 1.80 \mathrm{~mm}$ (range $6-15 \mathrm{~mm}$ ); $9.58 \pm 1.60 \mathrm{~mm}$ (range $7-13 \mathrm{~mm}$ ) and $9.42 \pm 2.06$ $\mathrm{mm}$ (range 6-15) in males and females respectively $(p=0.705)$. In both males and females, the transverse diameter was larger than the SI diameter $(p=0.004$ and 0.001 respectively). The mode values for transverse and SI diameters were $12 \mathrm{~mm}$ and $9 \mathrm{~mm}$ respectively. The aggregate mean diameter was $10.27 \mathrm{~mm}$. When the diameters of the ostium were corrected for weight of the hearts, the transverse and SI diameters were larger in females ( 0.042 and 0.036 respectively) than in males ( 0.034 and 0.03 respectively), giving a $p$ value of 0.001 and 0.014 respectively.

In females, the transverse diameter showed a negative correlation $(r=-0.171)$ with the weight of heart ( $p=0.357$ ) while the SI diameter showed a positive correlation $(r=0.205)$ which was not statistically significant $(p=0.269)$. In males, both ostium diameters showed positive correlation with weight of heart $(r=0.464, p=$ 0.002 and $r=0.175, p=0.261$ respectively) [see figure below].

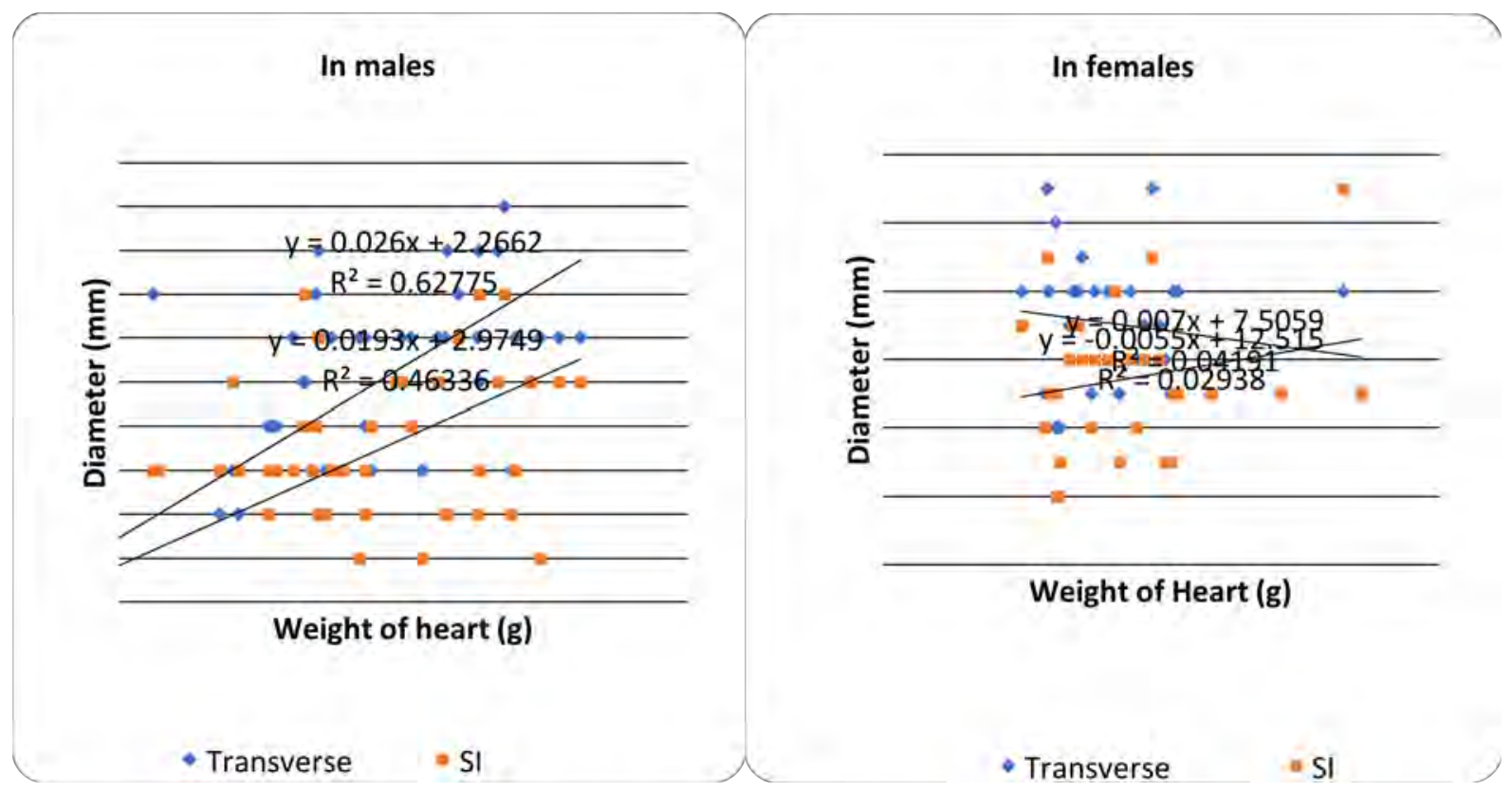

Figure 2: Correlation between ostium diameters and weight of heart

\section{DISCUSSION}

The mean diameter of CS ostium was $10.27 \mathrm{~mm}$ and the individual mean diameters for both genders revealed in the current study are within the range of $5-15 \mathrm{~mm}$ as reported by Habib et al (2009). The aggregate mean is comparable to $10.5 \mathrm{~mm}$ among the Japanese (Matsuyama et al., 2010) but higher than $8.94 \mathrm{~mm}$ and $9 \mathrm{~mm}$ reported among Colombian and Austrian populations (Pejkovic et al., 2008; Ballestros et al., 2010). The mean transverse diameter and supero-inferior (SI) diameters of the ostium were $11.04 \pm 1.88 \mathrm{~mm}$ (range $8-15 \mathrm{~mm}$ ) and 
$9.50 \pm 1.80 \mathrm{~mm}$ (range $6-15 \mathrm{~mm}$ ) respectively. This was higher than $6.6 \mathrm{~mm}(3-15 \mathrm{~mm})$ and $8 \mathrm{~mm}(3-15 \mathrm{~mm})$ reported by Pejkovic et al.(2008). Various studies reveal wide differences in CS ostial diameter. Although such variations may be due to differences in methodology, comparison of findings from different studies that used similar methodology suggest that the ostium diameter varies between populations [Table 1].

Table 1: Diameter of coronary sinus ostium reported in various populations.

\begin{tabular}{|c|c|c|c|}
\hline Reference & Populations & $\begin{array}{l}\text { Diameter of Ostium } \\
(\mathrm{mm})\end{array}$ & Method \\
\hline Current study, 2016 & Kenyan & 10.27 & Cadaveric \\
\hline Pejkovic et al., 2008 & Austrian & 9 & Cadaveric \\
\hline Ballesteros et al., 2010 & Columbian & 8.94 & Autopsy \\
\hline Matsuyama et al., 2010 & Japanese & 10.5 & Cadaveric \\
\hline Doig et al., 1995 & Canadian & 8.5 & Angiography \\
\hline Lee et al., 2006 & American & 16.9 & Venography \\
\hline Plass et al., 2008 & Swiss & 9.9 & Computed Tomography \\
\hline Ezhumalai et al.,2013 & Indian & 9.9 & Echocardiography \\
\hline Canbay et al., 2009 & Turkish & 9.3 & Angiography \\
\hline Koragoz et al., 2013 & Turkish & 12.5 & MDCT \\
\hline Mlynarski et al., 2011 & Russian & 14.2 & Computed tomography \\
\hline
\end{tabular}

The differences in body build affecting size of heart may account for this population variation (Anyanwu et al.2007). This implies that the design of cannulation devices should be based on the population.

The most remarkable observation of the current study is that when standardized using heart weight, females had significantly larger diameters $(p \leq 0.005)$. This is at variance with findings of Kousorov and Ivanov (2005) which revealed larger ostium diameters in males. It is not clear whether they standardized their measurements before the comparison was made. Hoskin et al. (2009) determined CS ostium diameter using CT angiography and documented that CS ostium diameter is not significantly different between males and females. Observations of the current study suggest that cannulation devices of similar diameters may not be applicable in both male and female subjects without major clinical consequences.

To demonstrate effect of heart weight on CS ostium diameter, Oliveira et al. (2007) reported a significant positive correlation between CS ostium diameter and heart weight in grams. Karaca et al. (2005) using formalin fixed cadaveric specimens also found that adult hearts weighing $<300 \mathrm{~g}$ had a mean ostium diameter of $8.72 \mathrm{~mm}$ compared to $10.76 \mathrm{~mm}$ in those weighing $>300 \mathrm{~g}$. In the current study, the correlation between heart weight and ostium diameters in females was positive for the SI diameter $(r=0.205)$. In males, both diameters increased with weight of heart. This suggests that catheterization is easier in heavier hearts. 
In conclusion, the diameter of coronary sinus ostium is larger in females than in males and shows positive correlation with weight of heart. These data should be considered during design and use of cardiac devices introduced through the coronary sinus. The coronary sinus ostial diameters should be determined before introduction of the devices.
Conflict of Interest: There is no conflict of interest.

Acknowledgment: I would like to acknowledge Acleus Murunga and Martin Inyimili of the Department of Human Anatomy for their support in harvesting the heart specimens, and Antonina Odock - Opiko for editing the manuscript.

\section{REFERENCES}

1. Anyanwu GE, Anibeze CIP, Akpuaka FC. 2007.Cardiothoracic ratio and body habitus in a Nigerian population. Biomedical Research; 18:119-122.

2. Ballesteros, Luis E, Ramirez, Luis M, Forero, Pedro L. 2010. Study of the coronary Sinus and its tributaries in Columbian subjects. Rev Colomb de Cardiol; 17:19-15.

3. Canbay A, Erastan H, Celebi OO, Aydogdu S, Dicker E. 2009. The comparison of coronary sinus anatomy in patients with supraventricular Arrythmia and in the normal population. Subat; 7: 17-21.

4. Cascade PN, Sneider MB, Koelling TM, Knight BP. 2001. Radiographic Appearance of Biventricular Pacing for the Treatment of Heart Failure. Am J Roentgenol; 177:1447-1450.

5. Doig JC, Saito J, Harris L, Downar E. 1994. Coronary sinus morphology in patients with atrioventricular junctional reentry tachycardia and other supraventricular tachyarrhythmia. Circulation; 92:436-441.

6. Ezhumalai B, Satheesh S, Anantha A, Pakkirisamy G, Balachander J, Selvaraj RJ. 2014. Coronary sinus diameter by echocardiography to differentiate atrioventricular nodal reentrant tachycardia from atrioventricular reentrant tachycardia. Cardiology J; Doi: 10.5603/ CJ. A2013.0088.

7. Felle P, Bannigan JG. 1994. Anatomy of the valve of the coronary sinus (Thebesian valve). Clinical Anatomy; 7: 10-12.

8. Glower DD, Bashore TM, Harrison JK, Wang A, Gehrig T, Rankin JS. 2009. Pure annular dilation as a cause of mitral valve regurgitation: a clinically distinct entity of female heart disease. $J$ Heart Valve Dis; 18:284-288.

9. Habib A, Lachman N, Christensen KN, Asirvatham SJ .2009. The anatomy of the coronary venous system for the cardiac electrophysiologist. Europace; 11:V15-V21.

10. Hoskins MH, Yoo D, Warren T, Langberg J. 2009. Gender differences in the anatomy of the interatrial septum. Circulation; 120:5685.

11. Koragoz A, Ucar O, Guarkan M, Kutucularoglu MG, Vural M, Diker E .2013. Multidetector computed anatomy of the coronary sinus in patients with supraventricular reentrant tachycardia. Kardiologia Polska; 71:911-916.

12. Kosourov AK, Ivanov VA. 2005. Structural features of heart coronary sinus in adult humans. Morfologia; 128:33-37.

13. Lee MS, Atman PS, Ninh D, Daniel B, James F, Prediman KS, et al. 2006. Coronary Sinus is Dilated and Outwardly Displaced in Patients With Mitral Regurgitation: Cathet and CardiovasC Interv; 67:490-494. 
14. Matsuyama $T$, Ishibashi-Ueda $H$, Ikeda $Y$, Yamada $Y$, Okamura $H$, Noda $T$, et al. 2010. The positional relationship between the coronary sinus musculature and the AV septal junction. Eur Soc Cardiol; 12: 719-725.

15. Mlynarski R, Mlynarska A, Tendera M, Sosnowki M. 2011. Coronary sinus ostium: key structure in the heart's anatomy from the electrophysiologist's point of view. Heart Vessels; 26:449-456.

16. Oliveira MI, Scanavacca MI, Correia AT, Sosa EA, Aiello VD. 2007. Anatomic relations and the Marshall vein: Importance for catheterization of the coronary sinus in ablation procedures. Eur Soc Cardiol; 9:915-919.

17. Pejkovic B, Krajnc I, Anderhuber F, Kosutic D. 2008. Anatomical variations of the coronary sinus ostium area of the human heart. $J$ Int Med Res; 36:314-321.

18. Plass A, Valenta I , Gaemperli O, Kaufmann P, Alkadhi H, Zund G, et al. 2008. Assessment of coronary sinus anatomy between normal and insufficient mitral valves by multi-slice computer tomography for mitral annuloplasty device implantations. Eur J Cardio Thorac Surg; . 33:583589.

19. Watkins DA, Sebitloane M, Engel ME, Mayosi BM. 2012. The burden of antenatal heart disease in South Africa: a systematic review. BMC Cardiovascular Disorder; 12:13.

20. Yuko-Jowi CA. 2012. African experience of humanitarian cardiovascular medicine: a Kenyan perspective. Cardiovasc Diagn Ther,. 2:231-239.

21. Zheng XZ, Yang B, Wu J. 2013. Sex specific assessment of reduced coronary sinus flow in nonhypertensive patients with coronary artery disease at rest. Lybian J Med; 8:21553. 